\title{
Long-Term Ultrasound Follow-Up of Incidentally Detected Thyroglossal Duct Cysts in Adults
}

\author{
(D)S.C. Kim, (D) H.Y. Sun, DH.S. Kim, and (DI. Ryoo
}

\begin{abstract}
BACKGROUND AND PURPOSE: There has been no previous study that used ultrasonography for longitudinal changes of thyroglossal duct cysts, to our knowledge. We assessed the prevalence and interval changes in incidentally detected thyroglossal duct cysts in adults.
\end{abstract}

MATERIALS AND METHODS: From January 2010 to December 2016, we identified 796 ultrasonography radiologic reports from 513 subjects that contained the words "thyroglossal" or "TGDC" among 54,369 participants. Of 513 subjects, 172 (M/F = 103:69, mean age, $53 \pm 11$ years) who underwent $\geq 2$ sonography studies were enrolled. Two reviewers determined ultrasonography features, including maximal diameter, location, internal echogenicity, wall thickness, and the presence of posterior enhancement, internal septa, and solid components.

RESULTS: The mean follow-up time of total 172 lesions was $2.01 \pm 1.13$ years. Thyroglossal duct cysts ranged from 2 to $32 \mathrm{~mm}$ (mean, $8.77 \pm$ $3.83 \mathrm{~mm}$ ) on the initial ultrasonography examination. On follow-up ultrasonography studies, 14 lesions (8.2\%) increased by $>2 \mathrm{~mm}$, while most thyroglossal duct cysts (133 lesions, $77.3 \%$ ) remained stable in size. During the follow-up period, 31 lesions (18.0\%) showed interval changes in ultrasonography features. There was no significant relationship between the presence of ultrasonography feature changes and size changes $(P=.12)$.

CONCLUSIONS: On ultrasonography, $0.9 \%$ of adults had incidental thyroglossal duct cysts. Most did not increase in size with time despite changes in various ultrasonography features. Therefore, we recommend performing an observation at long intervals of $2-3$ years for asymptomatic thyroglossal duct cysts, and we suggest that fine-needle aspiration can be suspended unless suspicious findings of malignancy are detected.

ABBREVIATIONS: TGDC $=$ thyroglossal duct cyst; US = ultrasonography

T hyroglossal duct cyst (TGDC) is the most common congenital neck mass, accounting for approximately $70 \%$ of congenital lesions of the neck. TGDCs typically present before 20 years of age; however, they present in adults as well. Although the reported prevalence of TGDCs varies among studies, it is generally estimated that $7 \%$ of the population has a TGDC and persistent remnants. ${ }^{1}$ High-resolution ultrasonography (US) is a readily available, noninvasive imaging technique commonly used for the initial investigation of the neck in daily practice. This has resulted in the incidental detection of TGDCs on neck US examinations. Due to the benign nature of TGDCs, it is recommended that most

Received May 21, 2018; accepted after revision September 29.

From the Department of Radiology (S.C.K., H.Y.S., H.S.K.), Seoul National University Hospital Healthcare System Gangnam Center, Seoul National University College of Medicine, Seoul, South Korea; and Department of Radiology (I.R.), Korea University Guro Hospital, Korea University College of Medicine, Seoul, South Korea.

Please address correspondence to H. Young Sun, MD, Department of Radiology, Seoul National University Hospital Healthcare System Gangnam Center, 152 Teheran Ro, Gangnam-gu, Seoul, 06236, Korea; e-mail: hysunsun@hanmail.net

http://dx.doi.org/10.3174/ajnr.A5882 patients in whom a TGDC is incidentally detected be observed only if they develop related symptoms or any suspicious findings consistent with a coexisting malignancy.

Prior studies have reported that TGDCs have a variable sonographic appearance ranging from typical anechoic to pseudosolid. ${ }^{2-5}$ Nevertheless, to the best of our knowledge, no previous study has used sonography to follow changes in TGDCs.

In this study, we assessed the prevalence and interval changes in incidentally detected TGDCs with a largest diameter of $\geq 3 \mathrm{~mm}$ in asymptomatic adults who underwent thyroid US examinations.

\section{MATERIALS AND METHODS}

This retrospective study was approved by the review boards of Seoul National University Hospital; informed consent was waived.

Adults 20-96 years of age who had undergone thyroid sonography during a comprehensive health screening examination from January 2010 to December 2016 were considered eligible for 
enrollment in our study. During the study period, 105,293 thyroid sonographic studies were performed in 54,369 consecutive subjects. Of 54,369 patients, 26,456 subjects were men and 27,913 were women. Among them, we identified 796 US radiologic reports from 513 subjects that contained the words "thyroglossal" or "TGDC." Of the 513 participants, 329 subjects underwent a single US examination, 103 subjects underwent 2 US studies, and the remaining subjects underwent $\geq 3$ US examinations during the study period. Among the 184 subjects who underwent $\geq 2$ US studies, 12 subjects were excluded because US images were not available. Finally, a total of 172 subjects $(M / F=103: 69$, mean age, $53 \pm 11$ years) with a TGDC were enrolled in our study.

\section{US Images}

Real-time gray-scale US was performed by various radiologists assigned arbitrarily according to the daily schedule of the hospital. Images were obtained using an 8- to $15-\mathrm{MHz}$ transducer (Acuson Sequoia; Siemens Medical Solutions, Mountain View, California), or a 5- to 14-MHz linear array transducer (iU22; Philips Medical Systems, Bothell, Washington).

Two US examinations were selected per subject. The first US study on which a TGDC was reported was designated the initial US study. The presence or absence of morphologic changes was then determined on follow-up US studies. The final study was defined as the most recent study if there were no morphologic changes, while if there were morphologic changes, the US study that first documented the changes was considered the final study. Two radiologists (S.C.K. and H.Y.S., with 5 and 3 years of experience in thyroid imaging) retrospectively reviewed static US images from 2 sets of US studies using a PACS and a consensus approach. Sonographic images were evaluated for the following features: maximal diameter, location of the mass, internal echogenicity, wall thickness, presence of posterior enhancement, internal septa, solid components, and presence or absence of the thyroid gland and any fistulous communication. Internal echogenicity was characterized as anechoic (definitely no internal echoes), homogeneously hypoechoic (hypoechoic relative to the strap muscle), homogeneously hyperechoic or pseudosolid (more echogenic than the strap muscle), or heterogeneous. The location was recorded as midline or lateral and at the suprahyoid/hyoid or infrahyoid level. Wall thickness was defined as imperceptible, thin (1-2 mm), or thick ( $\geq 2 \mathrm{~mm})$. Internal septa were classified as no septa, $1-3$ septa, and $\geq 4$ internal septa.

\section{Statistical Analysis}

Interval size changes between the initial and final US studies were calculated. We then classified subjects into the following 3 groups: 1) a decreased group, in which the interval size decrease was $>2$ $\mathrm{mm} ; 2$ ) a stable group, in which the interval size change was $\leq 2$ $\mathrm{mm}$; and 3) an increased group, in which the interval size increase was $>2 \mathrm{~mm}$. We used either the $\chi^{2}$ or the Kruskal-Wallis $\mathrm{H}$ test with Bonferroni correction to test for differences in demographic and US characteristics among the 3 groups. All analyses were performed with SPSS, Version 20 (IBM, Armonk, New York). $P<.05$ indicated a statistically significant difference.

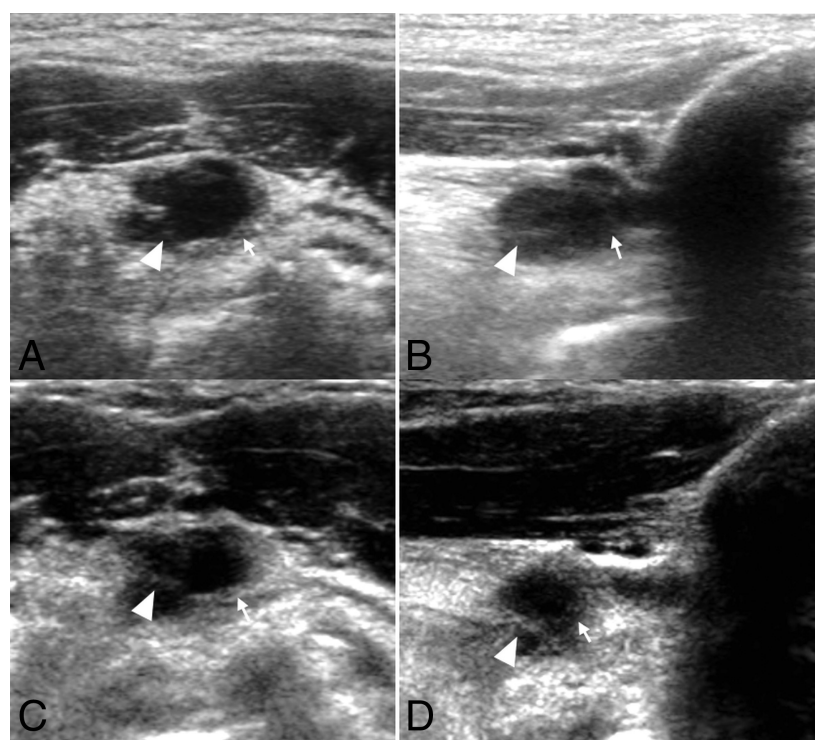

FIG 1. An 86-year-old man with an incidentally detected midline mass on US. Transverse $(A)$ and longitudinal $(B)$ sonograms show a uniformly anechoic thyroglossal duct cyst with few internal septa (arrowheads) and thin walls (white arrows). On follow-up US studies ( $C$ and $D$ ) at 2.5 years, the TGDC decreased by $4 \mathrm{~mm}$. There were no interval changes in US features.

\section{RESULTS}

The mean follow-up time between the initial and final US examination was $2.01 \pm 1.13$ years with a range of $0.42-6.83$ years. The follow-up time between the initial and the last US examination was $<1$ year for 61 lesions (35.5\%), between 1 and 2 years for 63 lesions (36.6\%), between 2 and 3 years for 41 lesions (23.8\%), and $\geq 4$ years for 7 lesions $(4.1 \%)$.

\section{US Features on Initial US Examinations}

TGDCs ranged from 2 to $32 \mathrm{~mm}$ (mean, $8.77 \pm 3.83 \mathrm{~mm}$ ) on the initial US examination. Among all lesions, 50 (29.1\%) were $>10$ $\mathrm{mm}$. One hundred sixty-five TGDCs $(95.9 \%)$ had a midline location. Eight TGDCs $(4.7 \%)$ presented at the infrahyoid level. Among them, 7 lesions were located at the lateral aspect.

Of the 172 lesions, 154 lesions (89.5\%) were truly anechoic, while 16 lesions $(9.3 \%)$ were homogeneously hypoechoic. One lesion $(0.6 \%)$ showed hyperechoic/pseudosolid echogenicity, and 1 lesion $(0.6 \%)$ had heterogeneous internal echoes. Regarding wall thickness, 20 lesions (11.6\%) had thin walls, while the walls of the other 152 lesions (88.4\%) were imperceptible. None of the 172 lesions had a wall thicker than $2 \mathrm{~mm}$.

Fifty lesions had 1-3 septa, while most TGDCs (121 lesions, $70.3 \%$ ) had no internal septa. One TGDC had $>4$ internal septa. Among 172 TGDCs, 146 lesions (84.9\%) showed posterior enhancement. Two TGDCs (1.2\%) had solid components.

No fistulous tracts were identified by sonography. All 172 individuals had thyroid glands in the normal location.

\section{Interval Changes on Follow-Up US Examinations}

On follow-up US studies, 25 TGDCs (14.5\%) decreased by $>2$ $\mathrm{mm}$ (Fig 1), while 14 lesions (8.2\%) increased by $>2 \mathrm{~mm}$. Most TGDCs (133 lesions, 77.3\%) remained stable in size (Fig 2). There were significant differences in follow-up intervals $(P=.009)$

AJNR Am J Neuroradiol 39:2356-59 Dec 2018 www.ajnr.org 2357 
among the 3 groups (decreased versus stable versus increased groups, Table). In post hoc analysis, the follow-up intervals of the decreased group were shorter than those of the stable group $(P=$ .005). Similarly, there were significant differences in initial diameters between the decreased and stable groups $(P=.011)$, but there were no significant differences between the decreased/stable and increased groups $(P=.31)$.

During the follow-up period, 31 lesions (18.0\%) showed interval changes in US features (Table). Eight lesions (4.7\%) showed changes in echogenicity; 11 lesions (6.4\%), in wall thickness; 14 lesions $(8.1 \%)$, in the presence of posterior enhancement; and 4 lesions $(2.3 \%)$, in internal septa. There was no case that showed a change in internal solid components. There were no significant differences in the presence of US feature changes among the 3 groups $(P=.12)$. Furthermore, there was no significant relationship between the type of US feature change and group identity $(P=.27)$.

\section{Clinicopathologic Results}

During the study period, fine-needle aspirations were performed for 2 lesions that had a solid component; for both cases, whitish

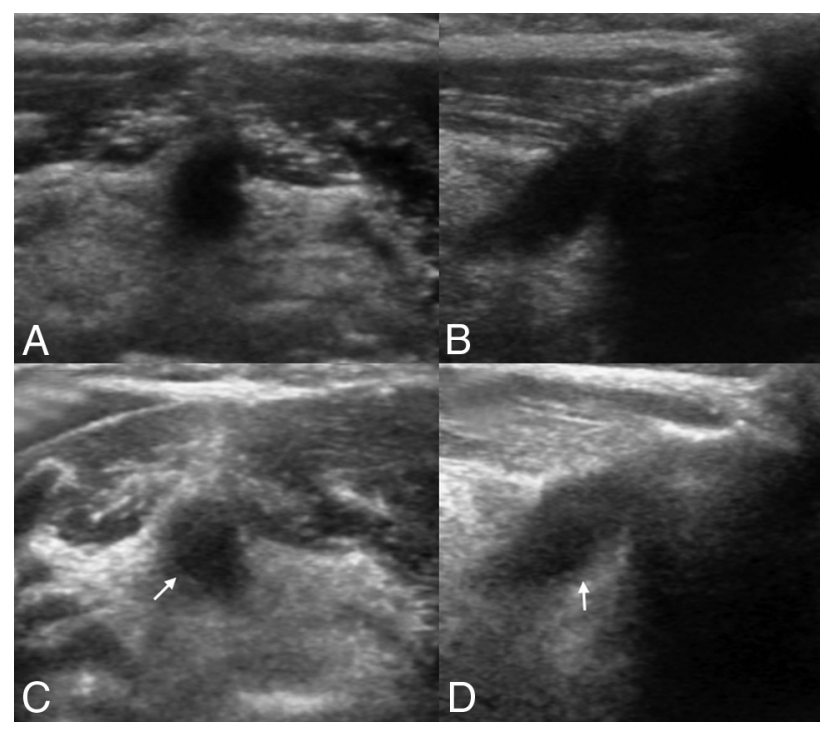

FIG 2. A 59-year-old man with an incidentally detected midline mass on US. Transverse $(A)$ and longitudinal $(B)$ sonograms demonstrate a uniformly anechoic thyroglossal duct cyst without a perceptible wall. On follow-up US ( $C$ and $D)$ at 6 years, the TGDC remained the same size, while there were interval changes in US features. White arrows indicate the thin walls of the TGDC.

Interval changes on follow-up US examinations ${ }^{a}$

\begin{tabular}{lcccc}
\hline & $\begin{array}{c}\text { Decreased } \\
\text { Group } \\
(\boldsymbol{n}=\mathbf{2 5})\end{array}$ & $\begin{array}{c}\text { Stable } \\
\text { Group } \\
(\boldsymbol{n}=\mathbf{1 3 3})\end{array}$ & $\begin{array}{c}\text { Increased } \\
\text { Group } \\
(\boldsymbol{n}=\mathbf{1 4})\end{array}$ & $\begin{array}{c}\boldsymbol{P} \\
\text { Value }\end{array}$ \\
\hline Follow-up intervals (mo) & $18.2 \pm 10.6^{\mathrm{b}}$ & $25.2 \pm 13.3^{\mathrm{b}}$ & $29.9 \pm 14.1$ & .009 \\
Maximal diameter on initial US (mm) & $10.8 \pm 5.8^{\mathrm{c}}$ & $8.3 \pm 3.2^{c}$ & $9.3 \pm 4.2$ & .042 \\
US feature changes of & $8(32 \%)$ & $20(15 \%)$ & $3(21.4 \%)$ & .12 \\
Internal echogenicity & 0 & 5 & 3 & .27 \\
Wall thickness & 2 & 8 & 1 & 1 \\
Presence of posterior enhancement & 4 & 9 & 0 & \\
Internal septa & 2 & 2 & 0 \\
Solid component & 0 & 0 & 0 \\
\hline
\end{tabular}

${ }^{a}$ Continuous variables are presented as means. Categoric variables are presented as numbers (percentages).

$b$ and c Post hoc analysis was evaluated by the Bonferroni correction method. The same letters indicate a significant difference between groups. mucinous fluid was aspirated and no malignant cells were detected. Two subjects underwent Sistrunk operations because their TGDCs increased in size and caused neck discomfort (Fig 3). Pathologic examination revealed cystic lesions lined by pseudostratified ciliated columnar epithelium, consistent with thyroglossal duct cysts.

\section{DISCUSSION}

Kurt et $\mathrm{al}^{6}$ reported that $15 \%$ of 80 adult cadavers had a TGDC, while Ellis and van Nostrand, ${ }^{7}$ on the basis of microscopic examination of 200 adult larynges, reported thyroglossal duct remnants in $7 \%$ of specimens. Yim et $\mathrm{al}^{8}$ reported a $0.1 \%$ prevalence of incidentally detected TGDCs among 60,663 CT and MR imaging scans of pediatric patients. In the present study, 513 of 54,369 subjects had TGDCs $(0.9 \%)$. We assume that some TGDCs were not described in radiologic reports because they were too small to detect or overlooked on screening thyroid US examinations. The prevalence of TGDCs will likely vary on the basis of the particular clinical setting, study population, and detection method. Our data therefore represent only the prevalence of incidental TGDCs on high-resolution US examinations of asymptomatic adults. Most TGDCs in our study were located at the suprahyoid/hyoid level rather than the infrahyoid level as in the study of Yim et al and other previous studies. ${ }^{8-10}$ Differences among studies in the methods used to detect TGDCs likely account for differences in their reported locations.

Ahuja et $\mathrm{al}^{11}$ reported that $<30 \%$ of a total of 40 TGDCs were truly anechoic in adults. However, almost all TGDCs in our study presented as a purely anechoic mass without any internal septa or solid components but with posterior enhancement, consistent with the typical sonographic description. ${ }^{2-5,12}$ This is likely because the TGDCs in the present study were relatively small and incidentally detected during screening of asymptomatic adults.

During the study period, $>90 \%$ of TGDCs remained the same size or decreased in size, even if there were interval changes in US features. Moreover, there was no correlation between the US feature that changed and whether size was stable, decreased, or increased. Previous studies indicated that a complex echo pattern accompanied by coarse internal debris and septa was due to the proteinaceous content of the cyst secreted by the cyst lining. ${ }^{11} \mathrm{On}$ the basis of this description, we believe that the US feature changes of TGDCs are more likely related to changes in the internal content or infection than to progression with time. Thus, we found no specific US feature that predicted an increase in the size of the TGDCs. Therefore, we believe that US can be implemented at long intervals of 2-3 years for asymptomatic TGDCs, even if there is a change in US features.

This study had some limitations. The most important one was that we enrolled TGDCs by clinicoradiologic diagnoses, not pathologic diagnoses. Although most TGDCs were clinically diagnosed and followed up without pathologic confirmation, Rayess et $\mathrm{al}^{13}$ reported coexisting malignancies in TGDCs inciden- 


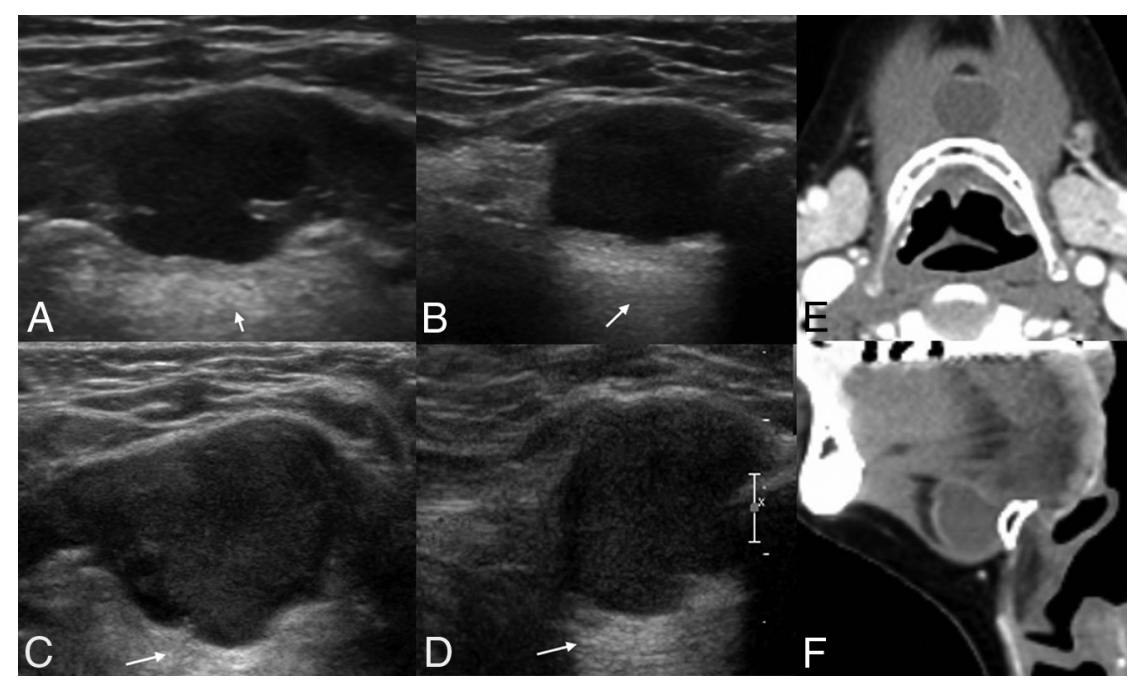

FIG 3. A 54-year-old man with an incidentally detected midline mass on US. Transverse $(A)$ and longitudinal (B) sonograms depict a truly anechoic thyroglossal duct cyst with posterior enhancement (white arrows). On follow-up US ( $C$ and $D$ ) at a 1 year, the TGDC shows a gradual increase of $5 \mathrm{~mm}$ and a pseudosolid appearance. He underwent a Sistrunk operation due to neck discomfort. Preoperative $C T$ images $(E$ and $F)$ demonstrate a uniformly hypoechoic cystic mass at the hyoid bone level. The TGDC was confirmed by pathologic examination of the surgical specimen, which showed no inflammation or hemorrhage.

tally diagnosed on the basis of the final pathologic analysis. Therefore, strictly speaking, we did not evaluate the development of TGDC carcinoma or its relationship to US feature changes on follow-up US images. However, no patient developed solid components or a mural mass with associated microcalcifications during the follow-up period; these are suspicious findings for malignancy. ${ }^{13,14}$ In addition, there was no evidence of malignancy in the 3 subjects who underwent pathologic diagnosis ( 2 who underwent operations due to a size increase and symptom development, and 1 individual who underwent fine-needle aspiration due to a size increase) during the follow-up period. Moreover, after the study period, we additionally evaluated follow-up US images of 5 individuals (among total 14 patients except 2 who underwent surgery, 5/12, 41.7\%) who had a TGDC that increased in size during the study period. None of the 5 lesions showed interval changes in size or developed solid components during the additional follow-up period of 1 year. Therefore, we argue that the possibility of a carcinoma arising within a TGDC was very low in the present study, as in prior studies. ${ }^{13-15}$ Furthermore, based on the results that no cancer was found at pathologic diagnosis and, even in cases of increased size of TGDCs, no newly suspicious findings for cancer at follow-up developed, we believe that size increase does not require the implementation of fine-needle aspiration. Nevertheless, our follow-up for the evaluation of malignant TGDCs was relatively short. Further studies with a longer follow-up and pathologic confirmation are needed.

\section{CONCLUSIONS}

TGDCs incidentally detected on high-resolution US examinations in adults are not uncommon. Most of these TGDCs do not increase in size with time despite changes in various US features. Therefore, we recommend performing an observation at long intervals of $2-3$ years for asymptomatic TGDCs, and we suggest that fine-needle aspiration can be suspended unless suspicious findings of malignancy are detected.

\section{REFERENCES}

1. Ewing CA, Kornblut A, Greeley C, et al. Presentations of thyroglossal duct cysts in adults. Eur Arch Otorhinolaryngol 1999;256:136-38 CrossRef Medline

2. Wadsworth DT, Siegel MJ. Thyroglossal duct cysts: variability of sonographic findings. AJR Am J Roentgenol 1994;163:1475-77 CrossRef Medline

3. Foley DS, Fallat ME. Thyroglossal duct and other congenital midline cervical anomalies. Semin Pediatr Surg 2006;15:70-75 CrossRef Medline

4. Koch BL. Cystic malformations of the neck in children. Pediatr Radiol 2005;35:463-77 CrossRef Medline

5. Choi HI, Choi YH, Cheon JE, et al. Ultrasonographic features differentiating thyroglossal duct cysts from dermoid cysts. Ultrasonography 2018;37:71-77 CrossRef Medline

6. Kurt A, Ortug C, Aydar Y, et al. An incidence study on thyroglossal duct cysts in adults. Saudi Med J 2007;28:593-97 Medline

7. Ellis $\mathrm{PD}$, van Nostrand AW. The applied anatomy of thyroglossal tract remnants. Laryngoscope 1977;87:765-70 CrossRef Medline

8. Yim MT, Tran HD, Chandy BM. Incidental radiographic findings of thyroglossal duct cysts: prevalence and management. Int J Pediatr Otorhinolaryngol 2016;89:13-16 CrossRef Medline

9. Moore KL, Persaud TV. The Developing Human: Clinically Oriented Embryology. Philadelphia: W.B. Saunders;1993:200-03

10. Thompson LD, Herrera HB, Lau SK. A clinicopathologic series of 685 thyroglossal duct remnant cysts. Head Neck Pathol 2016;10: 465-74 CrossRef Medline

11. Ahuja AT, King AD, King W, et al. Thyroglossal duct cysts: sonographic appearances in adults. AJNR Am J Neuroradiol 1999;20: 579-82 Medline

12. Ballenger JJ, Snow JB. Otorhinolaryngology: Head and Neck Surgery. Baltimore: Williams and Wilkins;1996:211-12

13. Rayess HM, Monk I, Svider PF, et al. Thyroglossal duct cyst carcinoma: a systematic review of clinical features and outcomes. Otolaryngol Head Neck Surg 2017;156:794-802 CrossRef Medline

14. Cignarelli M, Ambrosi A, Marino A, et al. Three cases of papillary carcinoma and three of adenoma in thyroglossal duct cysts: clinical-diagnostic comparison with benign thyroglossal duct cysts. $J$ Endocrinol Invest 2002;25:947-54 CrossRef Medline

15. Page CP, Kammerer WT, Haff RC, et al. Thyroid carcinomas arising in thyroglossal ducts. Ann Surg 1974;180:799-803 CrossRef Medline 